\title{
Numerical Solution of the Diffusion Equation with Restrictive Pade Approximation
}

\author{
Ahmet Boz*, Fevziye Gülsever \\ Departments of Mathematics, Dumlupinar University, Kütahya, Turkey \\ Email: *ahmet.boz@dpu.edu.tr
}

How to cite this paper: Boz, A. and Gülsever, F. (2016) Numerical Solution of the Diffusion Equation with Restrictive Pade Approximation. Journal of Applied Mathematics and Physics, 4, 2031-2037. http://dx.doi.org/10.4236/jamp.2016.411202

Received: October 10, 2016

Accepted: November 12, 2016

Published: November 15, 2016

Copyright $\odot 2016$ by authors and Scientific Research Publishing Inc. This work is licensed under the Creative Commons Attribution International License (CC BY 4.0). http://creativecommons.org/licenses/by/4.0/

\begin{abstract}
The problem of solving the linear diffusion equation by a method related to the Restrictive Pade Approximation (RPA) is considered. The advantage is that it has the exact value at certain $r$. This method will exhibit several advantages for example highly accurate, fast and with good results, etc. The absolutely error is still very small. The obtained results are compared with the exact solution and the other methods. The numerical results are in agreement with the exact solution.
\end{abstract}

\section{Keywords}

Restrictive Pade Approximation (RPA), Diffusion Equation, Finite Difference

\section{Introduction}

In this paper, we apply a new implicit method of high accuracy and the number of linear systems which to be solved are smaller than that for many famous known implicit methods of small step length. Therefore, our required machine time is less than that for the other implicit methods.

Restrictive Pade Approximation (RPA) for parabolic Partial Differential Equation (PDE) and Partial Difference Equations is a new technique done by İsmail and Elbarbary [1]. In addition, they studied numerical solution of the Convection Diffusion Equation [2]. RPA for hyperbolic PDE is done by İsmail and Younes [3] [4] [5]. Restrictive Taylor approximation solution for the parabolic PDE is studied by İsmail and Elbarbary [6]. Schrodinger and Singularly perturbed parabolic PDE studied by İsmail and Elbee$\operatorname{tar}$ [7] [8]. G. Gurarslan [9] studied numerical modelling of linear and nonlinear diffusion equations by compact finite difference method.

In this work, we consider the following one dimensional diffusion equation;

$$
u_{t}=u_{x x}+f(u), \quad 0<x<L
$$




$$
u_{t}=\left(D(u) u_{x}\right)_{x}, 0<x<L
$$

Subject to the initial condition

$$
u(x, 0)=f(x), 0<x<L
$$

and boundary conditions

$$
\begin{aligned}
& u(0, t)=g_{0}(x), t>0 \\
& u(1, t)=g_{1}(x), t>0
\end{aligned}
$$

The functions $f(u)$ are linear source functions. The function " $D(u)$ ” is the diffusion term that plays a crucial role in a wide range of applications in diffusion process. [10] [11] [12] The diffusion term $D(u)$ appears in several forms. Some of the well known diffusion proses are the fast and the slow diffusion process where the diffusion term is of the form $D(u)=u^{n}$ where $n<0$ and $n>0$ respectively.

\section{Method}

\subsection{Restrictive Pade Approximation (RPA)}

The Restrictive Pade Approximation (RPA) of function $f(x)$ is a particular type of rational functions, it can be written in the form [13] [14];

$$
R P A[M+\alpha / N]_{f(x)}(x)=\frac{\sum_{i=0}^{M} \alpha_{i} x^{i}+\sum_{i=1}^{\alpha} \varepsilon_{i} x^{M+i}}{1+\sum_{i=1}^{N} b_{i} x^{i}}
$$

where the positive integer $\alpha$ doesn't exceed the degree of the numerator $N, \alpha=0(1) N$,

$$
f(x)-R P A[M+\alpha / N]_{f(x)}(x)=0\left(x^{M+N+1}\right) .
$$

Let $f(x)$ have a Maclaurin Series;

$$
f(x)=\sum_{i=0}^{\infty} c_{i} x^{i}
$$

From Equations (6)-(8) we get, [1]

$$
\left(\sum_{i=0}^{\infty} c_{i} x^{i}\right)\left(1+\sum_{i=1}^{N} b_{i} x^{i}\right)-\sum_{i=0}^{N} a_{i} x^{i}-\sum_{i=1}^{\alpha} \varepsilon_{i} x^{i+M}=0\left(x^{M+N+1}\right)
$$

The varishing of the first $(M+N+1)$ power of $x$ on the left hand side of (9) implies a system of $(M+N+1)$ equations.

$$
\begin{aligned}
& a_{r}=c_{r}+\sum_{i=1}^{r} c_{r-i} b_{i}, r=0(1) M \quad\left(b_{i}=0 \text { if } i>M\right) \\
& c_{M+N-s}+\sum_{i=1}^{N} c_{M+N-i-s} b_{i}=\varepsilon_{N-s} \quad\left(c_{i}=0 \text { if } i>0\right)
\end{aligned}
$$

Hence we can determine the coefficient, $a_{i}$ and $b_{i}$ as a function of $\varepsilon_{i}, i=0(1) \alpha$, where the parameters $\varepsilon_{i}$ are to be determined, such that [15];

$$
f\left(x_{i}\right)=R P A[M+\alpha / N]_{f(x)}\left(x_{i}\right), i=1(1) \alpha
$$

Note: $\varepsilon_{i}=0, i=1(1) \alpha$ gives the classical Pade Approximation (RPA) of the form; 


$$
P A[M / N]_{f(x)}(x)=\frac{\sum_{i=0}^{M} \beta_{i} x^{i}}{1+\sum_{i=1}^{N} \gamma_{i} x^{i}} .
$$

The local truncation error form the RPA can be summarized by the following theorem.

THEOREM: If the function $f(x)$ has an $(n+1)^{+h}$ derivative, then for every argument $x$ there exist a number $\eta$ in the smallest interval I containing the set of points $\left\{x_{0}, x_{1}, x_{2}, \cdots, x_{\alpha}, x\right\}$, such that;

$$
R_{M, N, \alpha}(x)=f(x)-R P A[M+\alpha / N]_{f(x)}=\frac{\pi_{\alpha+1}(x)}{(\alpha+1) !}\left(R_{M, N, \alpha}(\eta)\right)^{(\alpha+1)}
$$

where $\prod_{\alpha+1}=x\left(x-x_{1}\right)\left(x-x_{2}\right) \cdots\left(x-x_{\alpha}\right)$ and $R_{M, N, \alpha}$ is the local truncation error for the RPA [1].

\subsection{Restrictive Pade Approximation of the Exponential Matrix}

The exponential matrix $\exp (r A)$ can be formally defined by the convergent power series,

$$
\exp (r A)=I+r A+\frac{r^{2}}{2 !} A^{2}+\frac{r^{3}}{3 !} A^{3}+\cdots=\sum_{n=0}^{\infty} \frac{r^{n}}{n !} A^{r}, A^{0}=I
$$

where $A$ is $(N-1) \times(N-1)$ matrix.

In the case of Restrictive Pade Approximation of single function the term $\varepsilon_{i}$ in Equation (4) can be reduced to the square matrix $\varepsilon_{i}$ in the case of Restrictive Pade approximation of the exponential matrix, where

$$
\varepsilon_{i}=\left(\begin{array}{cccc}
\varepsilon_{1, i} & & & 0 \\
& \varepsilon_{2, i} & \cdots & \\
& \vdots & \ddots & \vdots \\
0 & & \cdots & \varepsilon_{N-1, i}
\end{array}\right)
$$

for example,

$$
R P A[1 / 1]_{\exp (r A)}(r)=\left(I+\left(\varepsilon_{1}-\frac{1}{2} A\right) r\right)^{-1}\left(I+\left(\varepsilon_{1}+\frac{1}{2} A\right) r\right) .
$$

\section{Method of Solution}

We consider the diffussion for $f(u)=-u \quad[16]$. Thus, we use the equation;

$$
U_{t}=U_{x x}-U
$$

Subject to the initial condition;

$$
U(x, 0)=\sin x, 0<x<1
$$

and boundary conditions;

$$
\begin{aligned}
& U(0, t)=0, t>0 \\
& U(1, t)=0, t>0
\end{aligned}
$$


The exact solution of the Equation (16) is given by:

$$
U(x, t)=\mathrm{e}^{-2 t} \sin x
$$

Condiser the diffusion Equation (16) with the initial and boundary condition. The open rectangular domain is covered by a rectangular grid with spacing $h$ and $k$ in the $x$ and $t$ directions respectively. The grid point $(x, t)$ denoted by $(i h, j k)$ and $U(i h, j k)=U_{i, j}$ where $i=0(1) N \quad j$ is non-negaive integer.

The exact solution of grid representation of (6) is given by [3];

$$
U_{i, j+1}=\exp \left(k\left(D_{x}^{2}-1\right)\right) U_{i, j}
$$

The approximation of the partical derivatives $D_{x}^{2}$ at the grid point (ih, $\left.j k\right)$ will take the usual form:

$$
D_{x}^{2}=\frac{1}{h^{2}}\left(U_{i+1, j}-2 U_{i, j}+U_{i-1, j}\right)
$$

and according to central finite difference for mulation

$$
U=U_{i+1}-2 U_{i}+U_{i-1}
$$

The result of making this approximation is to replace (20) by the following equation

$$
U^{j+1}=\exp (r A) U^{j}, r=\frac{k}{h^{2}}
$$

where $U^{j}=\left(U_{1, j}, U_{2, j}, \cdots, U_{N-1, j}\right)^{\mathrm{T}}, N h=1$ and

$$
A=\left[\begin{array}{cccccc}
-2+2 h^{2} & 1-h^{2} & & & & \\
1-h^{2} & -2+2 h^{2} & 1-h^{2} & & & \\
& 1-h^{2} & -2+2 h^{2} & 1-h^{2} & & \\
& & \ddots & & & \\
& & & & & \\
& & & 1-h^{2} & -2+2 h^{2} & 1-h^{2} \\
0 & & & & 1-h^{2} & -2+2 h^{2}
\end{array}\right]_{(N-1) \times(N-1)}
$$

We use the

$$
R P A[1 / 1]_{\exp (r A)}(r)=\left(I+\left(\varepsilon-\frac{1}{2} A\right) r\right)^{-1} \cdot\left(I+\left(\varepsilon+\frac{1}{2} A\right) r\right)
$$

Equation to approximate the exponential matrix in Equation (23), then the approximate solution of grid representation of Equation (16) can take the form.

$$
\begin{aligned}
& \left(\varepsilon_{i}-\frac{1}{2}\left(1-h^{2}\right)\right) r U_{i-1, j+1}+\left[\left(\varepsilon_{i}-\left(1-h^{2}\right)\right) r+1\right] U_{i, j+1}+\left(\varepsilon_{i}-\frac{1}{2}\left(1-h^{2}\right)\right) r U_{i+1, j+1} \\
& =\left(\varepsilon_{i}+\frac{1}{2}\left(1-h^{2}\right)\right) r U_{i-1, j}+\left[\left(\varepsilon_{i}-\left(1-h^{2}\right)\right) r+1\right] U_{i, j}+\left(\varepsilon_{i}+\frac{1}{2}\left(1-h^{2}\right)\right) r U_{i+1, j}
\end{aligned}
$$

The constrat matrix $\varepsilon_{1}$ must determined by using the only one fact that the exact solution is given at first level. First choice of $\varepsilon_{1}=\left[\varepsilon_{i, j}\right]$ was the tridiagonal form: $\varepsilon_{i, i-1}=\varepsilon_{i, i}=\varepsilon_{i, i+1}=\varepsilon_{i}$ and $\varepsilon_{i, j}=0$. The second choise of $\varepsilon_{1}$ is the diagonal matrix 
$\varepsilon_{1}=\left[\varepsilon_{i, j}\right]: \varepsilon_{i, i}=\varepsilon_{i}, \varepsilon_{i, j}=0$ otherwise.

Other implicit methods can be derived if we use the possible Restrictive Pade Approximation RPA $[\mathrm{M} / \mathrm{N}]$, with non-negative integers $\mathrm{M}$ and $\mathrm{N}$.

\section{Findings}

The accuracy of Restrictive Pade Approximation method are compared in tables for various values of the time $t$. Tables give exact value, approximate value for compact finite difference method, approximate value for Restrictive Taylor Approximation, Restrictive Pade Approximation and absolute error for $\varepsilon=0.0032408523$. Comparison of the RPA results with RTA method for $k=0.0001, N=6, r=0.0036$ given below in tables.

The absolute error $(\mathrm{AE})$ is give by the following formula:

$$
\mathrm{AE}=\mid \text { Exact value }- \text { Approximate value } \mid \text {. }
$$

We tabulated all AE values at Table 1, Table 2 and Table 3.

Table 1. Absolute error (AE) for RPA at $t=0.01$.

\begin{tabular}{cccccc}
\hline $\boldsymbol{t}$ & $\boldsymbol{x}$ & Exact & RPA & RTA & AE [Present] \\
\hline & $1 / 6$ & 0.162611 & 0.162611 & 0.162611 & $1.02 \mathrm{E}-10$ \\
& $2 / 6$ & 0.320715 & 0.320715 & 0.320715 & $1.01 \mathrm{E}-10$ \\
& $3 / 6$ & 0.469932 & 0.469932 & 0.469932 & $1.01 \mathrm{E}-11$ \\
& $4 / 6$ & 0.606125 & 0.606125 & 0.606125 & $2.06 \mathrm{E}-11$ \\
& $5 / 6$ & 0.725520 & 0.725520 & 0.725520 & $1.12 \mathrm{E}-10$ \\
& 1 & 0.824808 & 0.824808 & 0.824808 & $1.15 \mathrm{E}-10$ \\
\hline
\end{tabular}

Table 2. Absolute error (AE) for RPA at $t=0.1$.

\begin{tabular}{cccccc}
\hline $\boldsymbol{t}$ & $\boldsymbol{x}$ & Exact & RPA & RTA & AE [Present] \\
\hline & $1 / 6$ & 0.135824 & 0.135824 & 0.135824 & $1.26 \mathrm{E}-9$ \\
& $2 / 6$ & 0.267884 & 0.267884 & 0.267884 & $1.16 \mathrm{E}-9$ \\
0.1 & $3 / 6$ & 0.392520 & 0.392520 & 0.392520 & $2.01 \mathrm{E}-11$ \\
& $4 / 6$ & 0.506278 & 0.506278 & 0.506278 & $1.25 \mathrm{E}-10$ \\
& $5 / 6$ & 0.606005 & 0.606005 & 0.606005 & $1.21 \mathrm{E}-9$ \\
& 1 & 0.688938 & 0.688938 & 0.688938 & $1.66 \mathrm{E}-9$ \\
\hline
\end{tabular}

Table 3. Absolute error (AE) for RPA at $t=1$.

\begin{tabular}{cccccc}
\hline $\boldsymbol{t}$ & $\boldsymbol{x}$ & Exact & RPA & RTA & AE [Present] \\
\hline & $1 / 6$ & 0.022451 & 0.022451 & 0.022451 & $2.54 \mathrm{E}-10$ \\
& $2 / 6$ & 0.044280 & 0.044280 & 0.044280 & $2.12 \mathrm{E}-10$ \\
& $3 / 6$ & 0.064883 & 0.064883 & 0.064883 & $4.25 \mathrm{E}-12$ \\
& $4 / 6$ & 0.083687 & 0.083687 & 0.083687 & $1.92 \mathrm{E}-11$ \\
& $5 / 6$ & 0.100172 & 0.100172 & 0.100172 & $2.04 \mathrm{E}-10$ \\
& 1 & 0.113880 & 0.113880 & 0.113880 & $2.52 \mathrm{E}-10$ \\
\hline
\end{tabular}




\section{Discussion \& Conclusion}

In this article, a numerical algorithm was applied in the one dimensional diffusion equation. Computed results were compared with other paper results in Table 1, Table 2 and Table 3. Especially, we compared it with Restrictive Taylor approximation method, because these methods have same properties. But as we have seen from the computational results, Restrictive Pade approximation method has more efficient results than restrictive Taylor approximation method. The proposed method results are quite satisfactory.

\section{References}

[1] İsmail, H.N.A. and Elbarbary, E.M.E. (1998) Restrictive Pade Approximation and Parabolic Partial Difference Equations. International Journal of Computer Mathematics, 66, 343-351. http://dx.doi.org/10.1080/00207169808804645

[2] İsmail, H.N.A. and Elbarbary, E.M.E. (1999) Highly Accurate Method for the ConvectionDiffusion Equations. International Journal of Computer Mathematics, 72, 271-280. http://dx.doi.org/10.1080/00207169908804850

[3] İsmail, H.N.A., Elbarbary, E.M.E. and Hassan, A.Y (2000) Highly Accurate Method for Solving Initial Boundary Value Problem for First Order Hyperbolic Differential Equation. International Journal of Computer Mathematics, 77, 251-261. http://dx.doi.org/10.1080/00207160108805063

[4] Ismail, H.N.A. and Hassan, A.Y. (2000) Restrictive Pade Approximation for Solving First Order Hyperbolic Partial Differential Equation. Journal of Institute of Mathematics and Computer Sciences, India, 11, 63-71.

[5] Ismail, H.N.A. and Hassan, A.Y. (2000) Restrictive Pade Approximation for Solving First Order Hyperbolic Partial Differntial Equation in Two Space Dimensions. Journal of Mathematics and Computer Science, India, 11, 159-166.

[6] Ismail, H.N.A. and Elbarbary, E.M.E. (2001) Restrictive Taylor Expansion and Parabolic Partial Differential Equations. International Journal of Computer Mathematics, 78, 73-82. http://dx.doi.org/10.1080/00207160108805097

[7] Ismail, H.N.A. and Elbeeatar, A.A. (2001) Restrictive Pade Approximation for the Solution of Singularity Perturbed Parabolic PDE. Journal of Mathematics and Computer Science, India, 12, 153-161.

[8] Ismail, H.N.A. and Elbeetar, A.A. (2002) Restrictive Pade Approximation for the Solution of Schrodinger Equation. International Journal of Computer Mathematics, 79, 603-613. http://dx.doi.org/10.1080/00207160210951

[9] Gurarslan, G. (2010) Numerical Modelling of Linear and Nonlinear Diffusion Equations by Compact Finite Difference Method. Applied Mathematics and Computation, 216, 24722478. http://dx.doi.org/10.1016/j.amc.2010.03.093

[10] Gurarslan, G. and Sari, M. (2011) Numerical Solutions of Linear and Nonlinear Diffusion Equation by a Differential Quadrature Method (DQM). International Journal for Numerical Methods in Engineering, 27, 69-77. http://dx.doi.org/10.1002/cnm.1292

[11] Meral, G. and Tezer-Sezgin, M. (2009) Differential Quadrature Solution of Nonlinear Reaction-Diffusion Equation with Relaxation-Type Time Integration. International Journal of Computer Mathematics, 86, 451-463. http://dx.doi.org/10.1080/00207160701600127

[12] Meral, G. and Tezer-Sezgin, M. (2011) The Differential Quadrature Solution of Nonlinear 
Reaction-Diffusion and Wave Equations Using Several Time-Integration Schemes. International Journal for Numerical Methods in Biomedical Engineering, 27, 461-632. http://dx.doi.org/10.1002/cnm.1305

[13] Ismail, H.N.A. and Elsayed, E.M. (1995) Restrictive Pade Approximation. Journal of Faculty of Education, Ain Shams University, Special Issue for the 1 st National Conference of Mathematical \& Physical Sciences and Applications, Cairo, 63-76.

[14] Ismail, H.N.A. and Elsayed, E.M. (1995) Differential and Integral Properties of Pade and Restrictive Pade Approximations. Journal of Faculty of Education, Ain Shams University, Special Issue for the 1 st National Conference of Mathematical \& Physical Sciences and Applications, Cairo, 77-90.

[15] Ismail, H.N.A. and Ekmekkawy, A.Y. (2001) Restrictive Pade Approximation for Solving Singularly Perturbed Initial-Boundary Value Problem for First-Order Hyperbolic Partial Differential Equation. 9th International Technology ASAT-9, Cairo, 61-69.

[16] Wazwaz, A.-M. (2007) The Variational Iteration Method: A Powerful Scheme for Handling Linear and Nonlinear Diffusion Equations. Computers and Mathematics with Applications, 54, 933-939. http://dx.doi.org/10.1016/j.camwa.2006.12.039

\section{Submit or recommend next manuscript to SCIRP and we will provide best service for you:}

Accepting pre-submission inquiries through Email, Facebook, LinkedIn, Twitter, etc.

A wide selection of journals (inclusive of 9 subjects, more than 200 journals)

Providing 24-hour high-quality service

User-friendly online submission system

Fair and swift peer-review system

Efficient typesetting and proofreading procedure

Display of the result of downloads and visits, as well as the number of cited articles

Maximum dissemination of your research work

Submit your manuscript at: http://papersubmission.scirp.org/

Or contact jamp@scirp.org 